\title{
The Outcome of Treatment for Patients with Borrmann Type 4 Advanced Gastric Cancer
}

\author{
Rie Tamaki 1,2*, Fumio Amano², Tohru Hashida1, Hironaga Satake ${ }^{3}$, Hisateru Yasui ${ }^{3}$, \\ Akihito Tsuji ${ }^{3,4}$ \\ ${ }^{1}$ Clinical Trial Management Center, Kobe City Medical Center General Hospital, Kobe, Japan \\ ${ }^{2}$ Laboratory of Biodefense \& Regulation, Osaka University of Pharmaceutical Sciences, Takatsuki, Japan \\ ${ }^{3}$ Department of Medical Oncology, Kobe City Medical Center General Hospital, Kobe, Japan \\ ${ }^{4}$ Department of Clinical Oncology, Faculty of Medicine, Kagawa University, Takamatsu, Japan \\ Email: ${ }^{\star}$ r.tamaki@hotmail.co.jp
}

How to cite this paper: Tamaki, R., Amano, F., Hashida, T., Satake, H., Yasui, H. and Tsuji, A. (2016) The Outcome of Treatment for Patients with Borrmann Type 4 Advanced Gastric Cancer. Journal of Cancer Therapy, 7, 953-962.

http://dx.doi.org/10.4236/jct.2016.712092

Received: October 21, 2016

Accepted: November 14, 2016

Published: November 17, 2016

Copyright $\odot 2016$ by authors and Scientific Research Publishing Inc. This work is licensed under the Creative Commons Attribution International License (CC BY 4.0).

http://creativecommons.org/licenses/by/4.0/

\section{(c) (i) Open Access}

\begin{abstract}
Introduction: The survival rate of patients with Borrmann type 4 advanced gastric cancer is extremely poor in comparison to patients with gastric cancers of other histological types. An optimal chemotherapeutic regimen has yet to be determined. Patients and Methods: We retrospectively examined the outcome of patients who were treated for Borrmann type 4 advanced gastric cancer from July 2011 and June 2015. Results: The data from 42 cases were collected for this study. Of the 42 cases, 13 cases (31.0\%) were locally advanced and 29 cases (69.0\%) were metastatic advanced. Median Overall Survival (OS) for locally advanced cancer was 29.6 months and for metastatic advanced cancer was 11.5 months. The presence or absence of peritoneal metastases did not affect survival (8.9 and 11.5 months, respectively; $\mathrm{p}=0.831$ ). In the 23 patients who received chemotherapy, S-1 plus cisplatin was prescribed as firstline treatment in 16 cases (69.5\%). Other treatment regimens included capecitabine plus cisplatin and S-1 plus oxaliplatinin one each (4.3\%), S-1 monotherapy in two $(8.6 \%)$, and capecitabine monotherapy, paclitaxel, and docetaxel in one each (4.3\%). We found no median OS difference between S-1 plus cisplatin and other treatments (20.7 and 19.3 months; $\mathrm{p}=0.094$ ). Conclusion: We found that $\mathrm{S}-1$ plus cisplatin treatment does not improve OS in patients with Borrmann type 4 advanced gastric cancer compared with other chemotherapeutic regimens.
\end{abstract}

\section{Keywords}

Gastric Cancer, Adenocarcinoma, Scirrhous, Cisplatin, Chemotherapy, Metastasis

\section{Introduction}

Gastric cancer is the third most common cause of cancer-related death in the world [1]. 
In 1926, Borrmann classified advanced gastric cancer into four gross types [2]. Borrmann type 4 was characterized by less differentiation, usually presenting as poorly differentiated adenocarcinoma, and by invasion of the entire wall of the stomach. Borrmann type 4 advanced gastric cancer was defined as follows: diffuse cancer, ulcers are almost invisible, and an ill-defined boundary. Despite recent advances in the treatment of gastric cancer, the prognosis of patients with Borrmann type 4 advanced gastric cancer remains extremely poor [3] [4], and the 5-year survival rate with this advanced gastric cancer is significantly lower than that of patients with other types of gastric cancer [5]. This can be seen in a report by The Japan Gastric Cancer Association Registration Committee of the treatment results and causes of death in patients with primary gastric cancer who were treated in Japan. Of 13,002 patients with primary gastric cancer, 5 -year survival by Borrmann type in resected cases regardless of stage was: type $0, n=$ 6869 (90.2\%); type $1, n=363$ (65.5\%); type 2, $n=1717$ (60.4\%); type $3, n=2575$ (46.0\%); type 4, $n=923$ (17.7\%); and type 5, $n=339$ (60.6\%) [6] [7]. Survival rates at 5 years after curative gastrectomy have ranged from $11 \%-38.4 \%$ [8] [9] [10]. This has led to the conclusion that surgery is not a curative treatment for Borrmann type 4 advanced gastric cancer [11] [12]. Indeed, no adequate therapeutic strategy for Borrmann type 4 advanced gastric cancer has been established.

In the 1990s, S-1 (TS-1; Taiho Pharmaceutical, Tokyo, Japan), an oral derivative of 5-FU, was developed for the treatment of gastric cancer [13] [14]. In Japan, S-1 rapidly established itself as a standard treatment with a high response rate of $46 \%$ as a single agent. Phase III trials proved the non-inferiority of S-1 compared with infusional 5-FU in the advanced/metastatic setting [15]. A phase III trial showed a better median survival time (MST) with the combination of S-1 plus cisplatin compared with S-1 monotherapy [16]. In addition, the combination of irinotecan and S-1 achieved longer median survival than S-1 monotherapy [17]. In Japan, advanced gastric cancer is mainly treated with S-1 alone or S-1 combined with other drugs.

As treatment for gastric cancer advances, it is expected that treatment for Borrmann type 4 advanced gastric cancer will also improve. Owing to its low incidence, however, only a few trials for this condition have been conducted. Here, we retrospectively examined the outcome in patients with Borrmann type 4 advanced gastric cancer treated with chemotherapy to assess survival.

\section{Patients and Methods}

\subsection{Patient Population and Data Collection}

Data from patients diagnosed with Borrmann type 4 advanced gastric cancer at Kobe City General Center Hospital between July 2011 and June 2015 were retrospectively collected for this study. The inclusion criterion was histologically confirmed primary gastric cancer Borrmann type 4 . The exclusion criteria were synchronous or metachronous cancers.

Clinical data was collected for each patient, including gender, age, and treatments. We used the 13th edition of the Japanese Classification of Gastric Carcinoma for data 
management [18]. The date of last follow-up and mortality were collected for all patients.

This retrospective study was approved by the Institutional Review Board of Kobe City Medical Center General Hospital and was conducted in accordance with the ethical principles mandated in Japan's Ethics Guidelines for Epidemiological Research.

\subsection{Statistical Considerations}

Univariate and multivariate analyses were performed using Cox's proportional hazard model to identify risk factors affecting overall survival (OS). OS was defined as the period from the diagnosis of type 4 advanced gastric cancer to the date of death from any cause. Patients who remained alive at the time of the last record were censored at that time. Survival curves were generated using the Kaplan-Meier method and the difference was analyzed by the log-rank test. P values $<0.05$ were considered statistically significant. Prognostic factors were evaluated by the Cox's proportional hazard model with a log-linear risk function. All statistical analysis was performed using Statistical Package for Social Science (SPSS) software (SPSS 23.0 Inc., Chicago, IL, USA).

\section{Results}

\subsection{Patient Characteristics}

Patient background at baseline is presented in Table 1. Forty-two cases were analyzed. Median age was 58 years (range, 32 - 81). Of the patients, 37 cases $(88.0 \%)$ had a baseline Eastern Cooperative Group performance status of 0 - 1. Thirteen cases (30.9\%) were locally advanced and 29 cases (69.0\%) were metastatic advanced. Fifteen cases (51.7\%) had peritoneal metastasis. As shown in Figure 1, among the 42 cases, 20 cases (52.3\%) were surgically resected. This included palliative resection in nine cases (one for bleeding from the primary lesion, five for stricture, and three for malnutrition) of metastatic advanced patients.

\subsection{Patient Outcome}

Chemotherapy was planned in 24 patients. However, one patient was transferred to another hospital before receiving chemotherapy (Figure 2), and chemotherapy was accordingly used as first-line treatment in 23 cases. As shown in Figure 3, the first-line treatment regimen consisted of S-1 plus cisplatin (SP) for 16 patients (69.5\%). Reasons for discontinuation of SP treatment were disease progression (90.0\%) and toxicity (10.0\%). Other treatment regimens included capecitabine plus cisplatin (XP) in one (4.3\%), S-1 plus oxaliplatin (SOX) in one (4.3\%), S-1 monotherapy in two (8.6\%), capecitabine monotherapy in one (4.3\%), paclitaxel in one $(4.3 \%)$ and docetaxel in one (4.3\%). After discontinuation of first-line treatment in 12 patients for disease progression and in one patient for toxicity, 13 patients (56.5\%) received only supportive care and 10 patients $(43.3 \%)$ received second-line chemotherapy. The second-line chemotherapy regimens consisted of paclitaxel in eight patients, irinotecan (CPT-11) in one, and S-1 monotherapy in one. After discontinuation of second-line treatment due to 
Table 1. Patient characteristics $(n=42)$.

\begin{tabular}{|c|c|c|}
\hline & & $n(\%)$ \\
\hline Age, years & Median & 58 (Range $32-81$ ) \\
\hline \multirow[t]{2}{*}{ Gender } & Male & $17(40.5 \%)$ \\
\hline & Female & $25(59.5 \%)$ \\
\hline \multirow[t]{2}{*}{ ECOG performance status } & 0,1 & $37(88.0 \%)$ \\
\hline & 2 & $5(12.0 \%)$ \\
\hline \multirow[t]{4}{*}{ Stage } & I & $1(2.3 \%)$ \\
\hline & II & $2(4.7 \%)$ \\
\hline & III & $10(23.0 \%)$ \\
\hline & IV & $29(69.0 \%)$ \\
\hline \multirow[t]{2}{*}{ Histological type } & Diffuse & $39(92.9 \%)$ \\
\hline & Interstitial & $3(7.1 \%)$ \\
\hline \multirow[t]{2}{*}{ HER 2 status } & Positive & $2(4.8 \%)$ \\
\hline & Negative & $40(95.2 \%)$ \\
\hline \multirow[t]{2}{*}{ Gastrectomy } & Yes & $20(52.3 \%)$ \\
\hline & No & $22(47.7 \%)$ \\
\hline \multirow[t]{2}{*}{ Degree of tumor extent } & Metastatic & $29(69.0 \%)$ \\
\hline & Locally advanced & $13(31.0 \%)$ \\
\hline \multirow[t]{4}{*}{ Metastatic site } & Peritoneum & $15(51.7 \%)$ \\
\hline & Abdominal lymph nodes & $7(24.1 \%)$ \\
\hline & Liver & $1(3.4 \%)$ \\
\hline & Other & $6(20.6 \%)$ \\
\hline
\end{tabular}

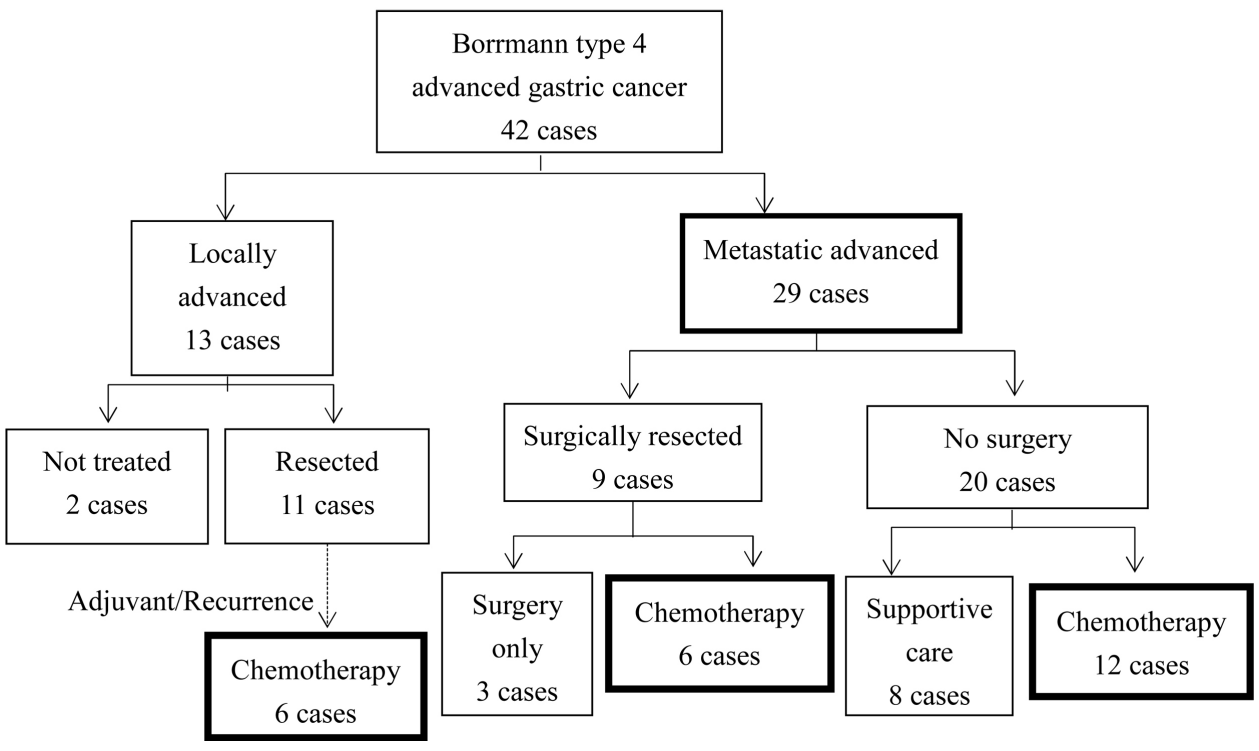

Figure 1. Diagram of the study. 


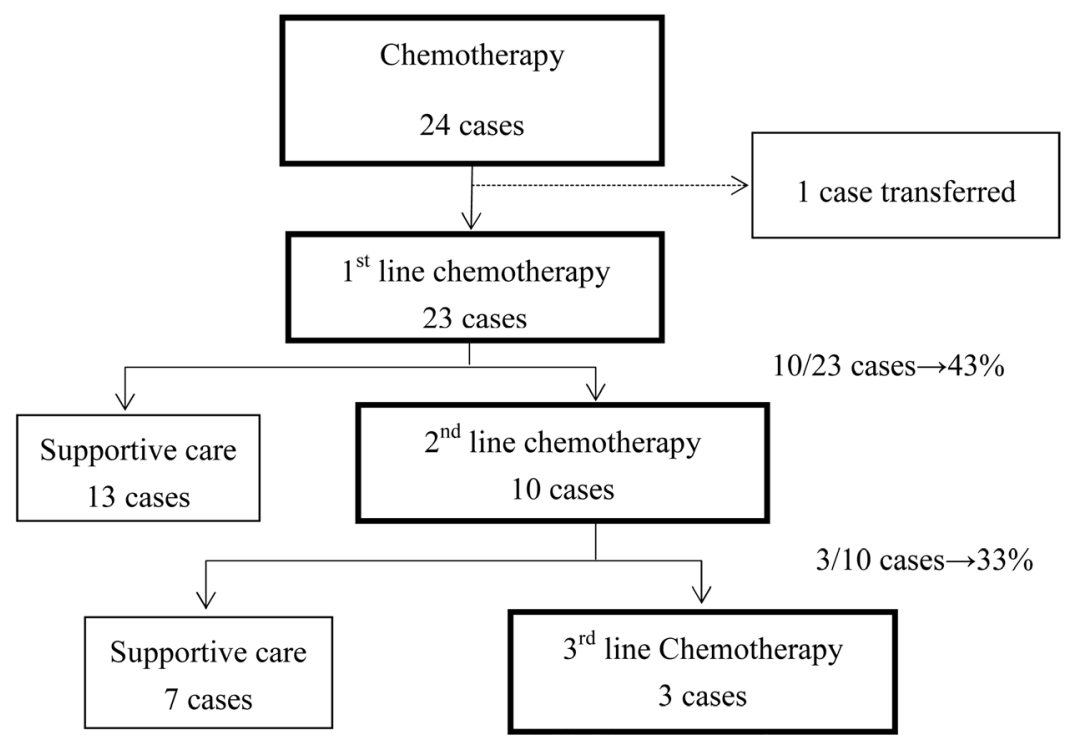

Figure 2. Diagram of the chemotherapy treatment patients.

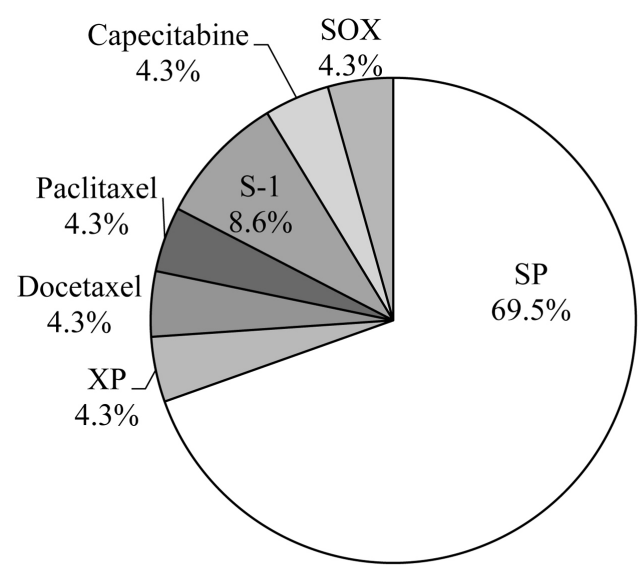

SP : $\mathrm{S}-1+$ cisplatin

XP : capecitabine + cisplatin

SOX : $\mathrm{S}-1+$ oxaliplatin

(a)

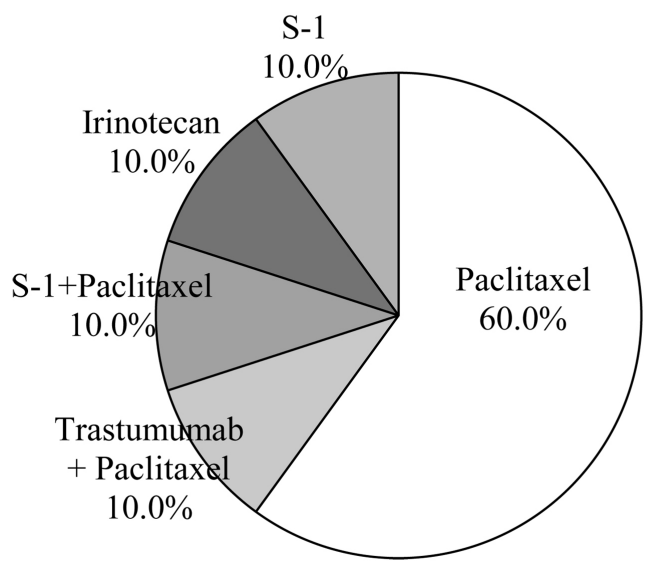

(b)

Figure 3. Chemotherapy treatment ratio. (a) 1st line chemotherapy $(n=23)$. (b) 2nd line chemotherapy $(n=10)$. 
disease progression, 7 patients (7\%) received only supportive care and 3 patients received third-line chemotherapy, two with docetaxel (66.6\%) and one with S-1 plus paclitaxel (33.3\%). Figure 4 shows the OS of locally advanced cases and metastatic advanced cases. The median OS of locally advanced cases was 29.6 months ( $95 \%$ confidence interval [CI]: $16.8-42.3$ months) while that of metastatic advanced cases was 11.5 months (95\% CI: $2.1-20.8$ months; $\mathrm{p}=0.019$ ). Among locally advanced patients, one patient was stage I, two patients were stage II, and ten patients were stage III. Curative resection was performed in 11 of the locally advanced cases (84.6\%). There was a statistically significant difference between the OS of locally advanced and metastatic advanced cases $(\mathrm{p}=0.019)$.

In this study, the median OS for patients with peritoneal metastases was 8.9 months (95\% CI: 0 - 21.9 months) while that for no peritoneal metastases was 11.5 months (95\% CI: 0 - 29.0 months; $\mathrm{p}=0.831$ ) (Figure 5), indicating that peritoneal metastases were unrelated to OS. The median OS for patients treated with first-line SP was 20.7 months (95\% CI: 12.9 - 28.4 months) and that patients with any other chemotherapy was 19.3 months (95\% CI: 5.1 - 33.4 months) $\mathrm{p}=0.994$ (Figure 6).

\section{Discussion}

In this study, Borrmann type 4 gastric cancer tended to affect younger patients, and was particularly more prevalent in female patients (59.5\%) and was mostly of the diffuse type (92.9\%). Because the patients were mainly HER 2 status-negative (95.2\%), they were not candidates for trastuzumab [19]. In addition, at the time of diagnosis, most patients (69.0\%) had unresectable disease, most with peritoneal dissemination (51.7\%). These are the major reasons for the poorer prognosis of Borrmann type 4 advanced gastric cancer [20].

Compared with locally advanced cases, metastatic cases had a significantly lower median OS, at 29.6 months vs. 11.5 months $(p=0.019)$, respectively. The OS benefit

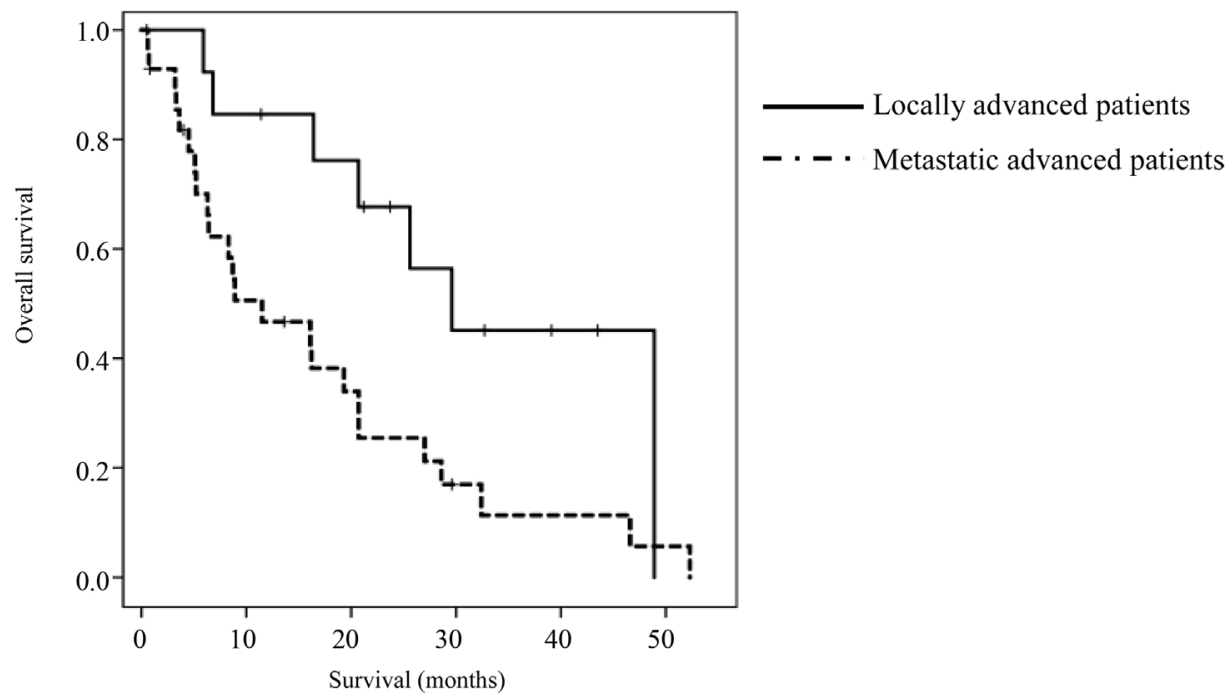

Figure 4. Overall survival of locally advanced cases and metastatic advanced cases $(n=42)$. 


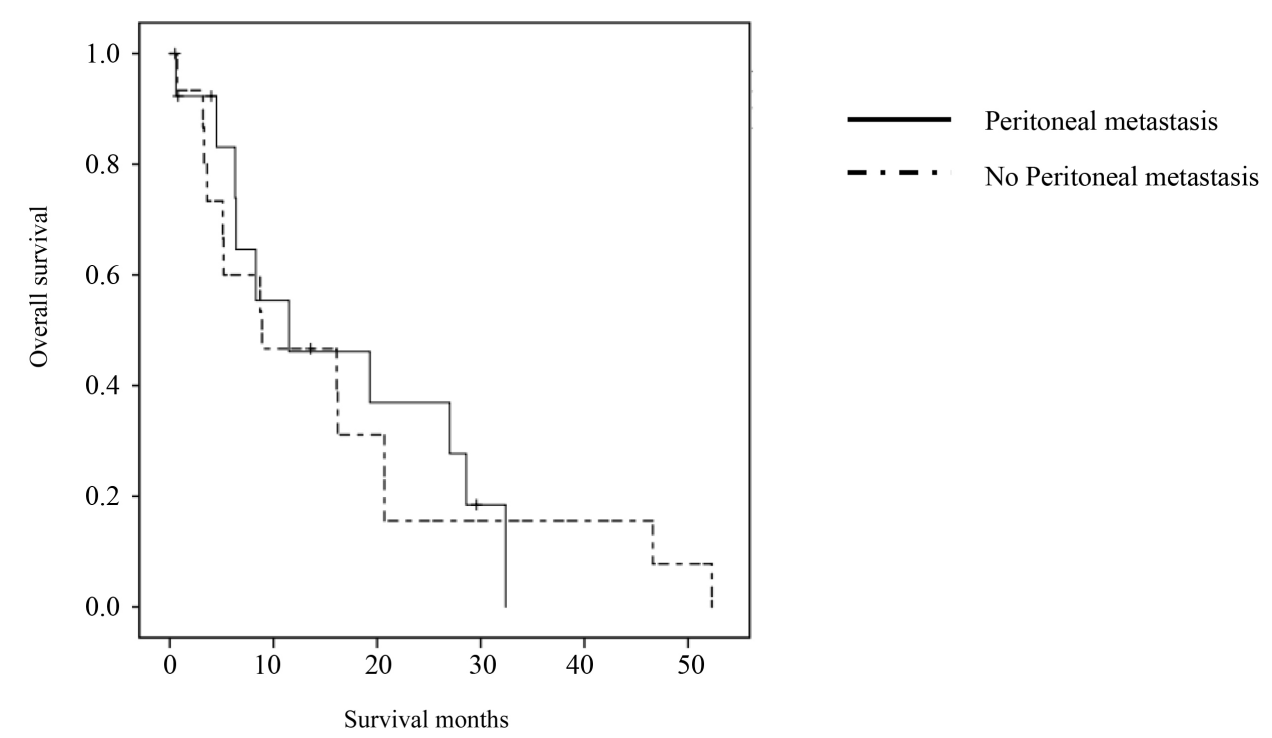

Figure 5. Overall survival of patients with and without peritoneal metastasis $(n=29)$.

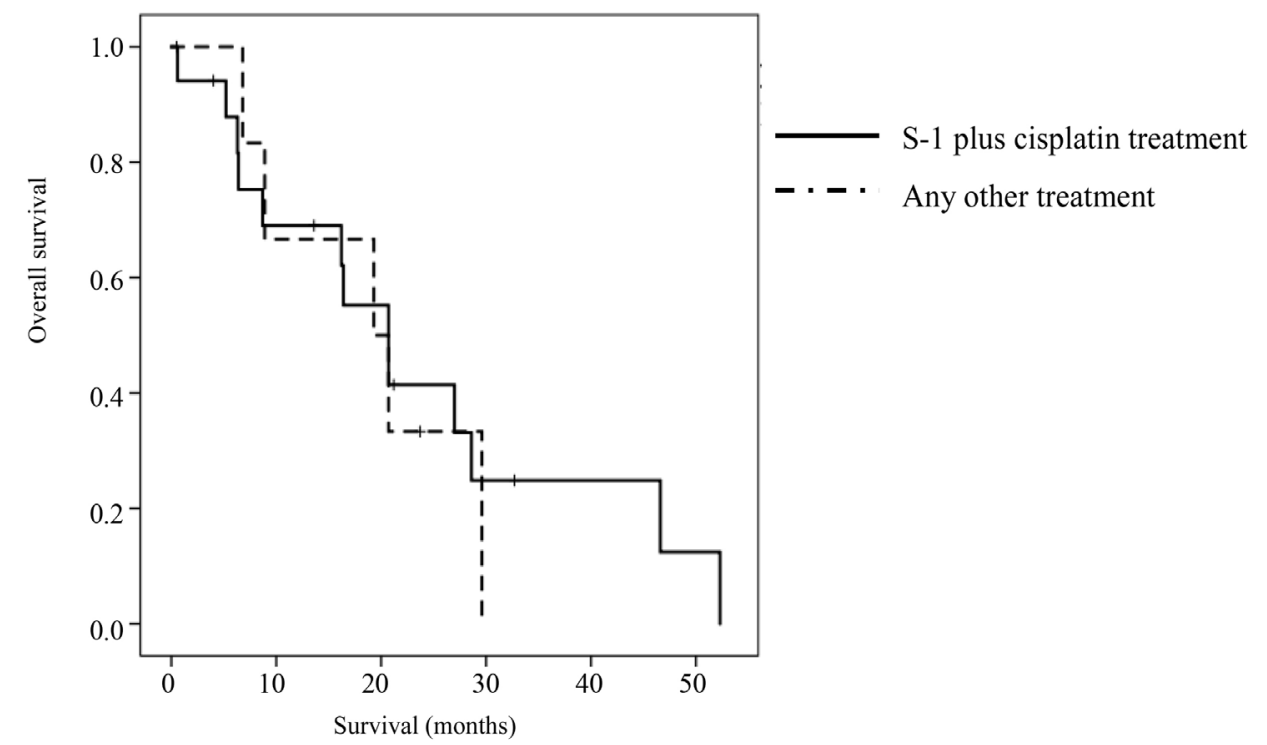

Figure 6. Overall survival of patients with S-1 plus cisplatin treatment and patients on any other treatments $(n=23)$.

in locally advanced patients has been reported, but Borrmann type 4 advanced gastric cancer is seldom diagnosed at an early stage (stage IV vs. stage I-III was $69.0 \%$ vs. $30.9 \%)$.

Generally, we chose a fluorinated pyrimidine plus platinum combination, S-1 plus cisplatin, as treatment for metastatic advanced cases. There were no significant differences in median OS between patients treated with SP (20.7 months, 95\% CI: 12.9 - 28.4 months) and those with any other chemotherapy (19.3 months, $95 \%$ CI: 5.1 - 33.4 months; $\mathrm{p}=0.994)$. These results suggest that SP does not have sufficient efficacy for the treatment of patients with Borrmann type 4 advanced gastric cancer. 
Only $43 \%$ of patients received second-line chemotherapy in this study (Figure 2). In contrast, $75 \%$ of patients in a recent Japanese phase III trial (SPIRITS; S-1 vs. S-1 plus cisplatin) for advanced gastric cancer received second-line treatment [16]. We consider that patients with Borrmann type 4 advanced gastric cancer, who progressed during first-line treatment, were in poorer general condition, so most of them might have missed the opportunity to receive second-line chemotherapy.

It is important for patients with Borrmann type 4 advanced gastric cancer to receive effective chemotherapy as first-line treatment to improve survival. Reasons for this include the unreliability of the administration and absorption of oral agents in these patients due to stricture, the high risk of complications, and the inability to receive the hydration that is required for renal protection from cisplatin. Oxaliplatin is a thirdgeneration platinum compound that was developed to provide improved tolerability and administration over cisplatin. The non-inferiority of oxaliplatin-based regimens to cisplatin-based regimens was demonstrated in the Revised European-American Lymphoma (REAL)-2 study. This background therefore indicates the need to develop novel chemotherapeutic regimens with non-oral agents, with no need for hydration, and with high feasibility for patients with this disease [21].

A previous clinical study demonstrated that gastric cancer patients with severe peritoneal metastases receiving 5-FU-based chemotherapy as first-line treatment had a median time to treatment failure (TTF) and OS of 1.9 and 4.6 months, respectively [22]. 5-FU-based chemotherapy for gastric cancer patients with severe peritoneal metastases was feasible, but its efficacy was unsatisfactory. Recent phase III trials have demonstrated the non-inferiority of chemotherapy using oral fluoropyrimidines, such as capecitabine or S-1, compared to 5-FU-based chemotherapy [15] [22] [23]. Oral fluoropyrimidine and cisplatin combination therapy is a standard regimen worldwide [3]. Although 5-FU is one of the most commonly used drugs in patients with gastrointestinal cancers, systemic 5-FU chemotherapy has a limited response rate [24]. A new treatment for Borrmann type 4 advanced gastric cancer, including $5-\mathrm{FU}$, is urgently required.

We found that SP treatment does not improve OS. Further research into chemotherapy as a treatment for patients with Borrmann type 4 advanced gastric cancer is required.

\section{References}

[1] Naghavi, M. (2015) The Global Burden of Cancer 2013 Global Burden of Disease Cancer Collaboration. JAMA Oncology, 1, 505-527. http://dx.doi.org/10.1001/jamaoncol.2015.0735

[2] Borrmann, R. (1926) Geschwülste des Magens and Duodenums. In: Borchardt, H., Borrmann, R. and Christeller, E., Eds., Verdauungsschlauch: Erster Teil Rachenund Tonsillen, Speiseröhre Magen und Darm, Bauchfell, Springer, Vienna, 812-1054.

[3] Narikazu, B. (2008) Chemotherapy for Metastatic Gastric Cancer in Japan. International Journal of Clinical Oncology, 13, 483. http://dx.doi.org/10.1007/s10147-008-0847-2

[4] An, J.Y., Kang, T.H. and Choi, M.G. (2008) Borrmann Type IV: An Independent Prognostic Factor Forsurvival in Gastric Cancer. Journal of Gastrointestinal Surgery, 12, 1364-1369. http://dx.doi.org/10.1007/s11605-008-0516-9 
[5] Chen, C.Y., Wu, C.W., Lo, S.S., Hsieh, M.C. and Lui, W.Y. (2002) Peritoneal Carcinomatosis and Lymph Node Metastasis Are Prognostic Indicators in Patients with Borrmann Type IV Gastric Carcinoma. Hepatogastroenterology, 49, 874-877.

[6] Nashimoto, A., Akazawa, K. and Isobe, Y. (2013) Gastric Cancer Treated in 2002 in Japan: 2009 Annual Report of the JGCA Nationwide Registry. Gastric Cancer, 16, 1-27. http://dx.doi.org/10.1007/s10120-012-0163-4

[7] Otsuji, E., Kuriu, Y. and Okamoto, K. (2004) Outcome of Surgical Treatment for Patients with Scirrhous Carcinoma of the Stomach. The American Journal of Surgery, 188, 327-332. http://dx.doi.org/10.1016/j.amjsurg.2004.06.010

[8] Kim, D.Y., Kim, H.R. and Kim, Y.J. (2002) Clinicopathological Features of Patients with Borrmann Type IV Gastric Carcinoma. ANZ Journal of Surgery, 72, 739-742. http://dx.doi.org/10.1046/j.1445-2197.2002.02523.x

[9] Yoshikawa, T., Tsuburaya, A. and Kobayashi, O. (2001) Should Scirrhous Gastric Carcinoma Be Treated Surgically? Clinical Experiences with 233 Cases and a Retrospective Analysis of Prognosticators. Hepatogastroenterology, 48, 1509-1512.

[10] Kinugasa, S., Abe, S. and Tachibana, M. (1997) Surgically Curable and Incurable Scirrhous Carcinomas of the Stomach. Journal of Surgical Oncology, 65, 194-200. http://dx.doi.org/10.1002/(SICI)1096-9098(199707)65:3<194::AID-JSO9>3.0.CO;2-1

[11] Maehara, Y., Moriguchi, S. and Orita, H. (1992) Lower Survival Rate for Patients with Carcinoma of the Stomach of Borrmann Type IV after Gastric Resection. Surgery, Gynecology \& Obstetrics, 175, 13-16.

[12] Kim, E.Y., Yoo, H.M., Song, K.Y. and Park, C.H. (2016) Limited Significance of Curative Surgery in Borrmann Type IV Gastric Cancer. Medical Oncology, 33, 69. http://dx.doi.org/10.1007/s12032-016-0783-3

[13] Fukushima, M., Satake, H., Uchida, J., Shimamoto, Y., Kato, T., Takechi, T., Okabe, H., Fujioka, A., Nakano, K., Ohshimo, H., Takeda, S. and Shirasaka, T. (1998) Preclinical Antitumor Efficacy of S-1: A New Oral Formulation of 5-Fluorouracil on Human Tumorxenografts. International Journal of Oncology, 13, 693-698.

[14] Koizumi, W., Kurihara, M., Nakano, S. and Hasegawa, K. (2000) Phase II Study of S-1, a Novel Oral Derivative of 5-Fluorouracil, in Advanced Gastric Cancer. For the S-1 Cooperative Gastric Cancer Study Group. Oncology, 58, 191-197. http://dx.doi.org/10.1159/000012099

[15] Narikazu, B., Seiichiro, Y., Haruhiko, F., Kuniaki, S., Toshihiko, D., Akira, S., Wasaburo, K., Hiroshi, S., Kensei, Y., Hiroya, T., Junichiro, N. and Atsushi, O. (2009) Fluorouracil Versus Combination of Irinotecan Plus Cisplatin versus S-1 in Metastatic Gastric Cancer: A Randomised Phase 3 Study. Lancet Oncology, 10, 1063-1069. http://dx.doi.org/10.1016/S1470-2045(09)70259-1

[16] Wasaburo, K., Narahara, H., Hara, T., Takagane, A., Akiya, T. and Masakazu, T. (2008) S-1 Plus Cisplatin versus S-1 Alone for First-Line Treatment of Advanced Gastric Cancer (SPIRITS Trial): A Phase III Trial. Lancet Oncology, 9, 215-221. http://dx.doi.org/10.1016/S1470-2045(08)70035-4

[17] Hiroyuki, N., Hiroyasu, I., Hiroshi, I., Akira, T., Keisho, C., Haruhiko, I., Taito, E., Hiroshi, F., Chikuma, H. and Yuh, S. (2011) Randomized Phase III Study Comparing the Efficacy and Safety of Irinotecan Plus S-1 with S-1 Alone as First-Line Treatment for Advanced Gastric Cancer (Study GC0301/TOP-002). Gastric Cancer, 14, 72-80. http://dx.doi.org/10.1007/s10120-011-0009-5

[18] Aikou, T., Hokita, S. and Natsugoe, S. (2001) Japanese Classification of Gastric Carcinoma 
(13th Edition, June 1999): Points to Be Revised. Nihon Rinsho, 59, 159-165. (In Japanese)

[19] Bang, Y.J., Custem, E.V., Feyereislova, A., Chung, H.C., Shen, L., et al. (2010) Trastuzumab in Combination with Chemotherapy versus Chemotherapy Alone for Treatment of HER2-Positive Advanced Gastric or Gastro-Oesophageal Junction Cancer (ToGA): A Phase 3, Open-Label, Randomised Controlled Trial. Lancet Oncology, 376, 687-697. http://dx.doi.org/10.1016/S0140-6736(10)61121-X

[20] Hur, H., Lee, H.H., Jung, H., Song, K.Y., Jeon, H.M. and Park, C.H. (2010) Predicting Factors of Unexpected Peritoneal Seeding in Locally Advanced Gastric Cancer: Indications for Staging Laparoscopy. Journal of Surgical Oncology, 1, 753-757. http://dx.doi.org/10.1002/jso.21685

[21] Kenichi, N., Junki, M., Haruhiko, F., Kuniaki, S., Yasuhiro, S. and Atsushi, O. (2003) Randomized Phase III Trial of Fluorouracil Alone versus Fluorouracil Plus Cisplatin versus Uracil and Tegafur Plus Mitomycin in Patients with Unresectable, Advanced Gastric Cancer: The Japan Clinical Oncology Group Study (JCOG9205). Journal of Clinical Oncology, 21, 54-59. http://dx.doi.org/10.1200/JCO.2003.04.130

[22] Satoru, I., Takako, N., Kenichi, N., Atsuo, T., Ken, K., Tetsuya, H., Yasuhide, Y. and Yasuhiro, S. (2012) First-Line Fluorouracil-Based Chemotherapy for Patients with Severe Peritoneal Disseminated Gastric Cancer. Gastric Cancer, 15, 21-26. http://dx.doi.org/10.1007/s10120-011-0056-y

[23] David, C., Naureen, S., Sheela, R., Timothy, I., Marianne, N., Fareeda, C., et al. (2008) Capecitabine and Oxaliplatin for Advanced Esophagogastric Cancer. New England Journal of Medicine, 358, 36-46. http://dx.doi.org/10.1056/NEJMoa073149

[24] Kang, Y.K., Kang, W.K., Shin, D.B., Chen, J., Xiong, J., Wang, J., Lichinitser, M., Guan, Z., Khasanov, R., Zheng, L., Philco-Salas, M., Suarez, T., Santamaria, J., Forster, G. and McCloud, P.I. (2009) Capecitabine/Cisplatin versus 5-Fluorouracil/Cisplatin as First-Line Therapy in Patients with Advanced Gastric Cancer: A Randomised Phase III Noninferiority Trial. Annals of Oncology, 20, 666-673. http://dx.doi.org/10.1093/annonc/mdn717

\section{Submit or recommend next manuscript to SCIRP and we will provide best service} for you:

Accepting pre-submission inquiries through Email, Facebook, LinkedIn, Twitter, etc. A wide selection of journals (inclusive of 9 subjects, more than 200 journals)

Providing 24-hour high-quality service

User-friendly online submission system

Fair and swift peer-review system

Efficient typesetting and proofreading procedure

Display of the result of downloads and visits, as well as the number of cited articles

Maximum dissemination of your research work

Submit your manuscript at: http://papersubmission.scirp.org/

Or contact jct@scirp.org 